\title{
$\underset{1}{10}$ CONAERG
}

\section{ERGONOMIA COGNITIVA: PERCEPÇÃO DE INTEGRALIDADE DO TRABALHADOR EM ASPECTOS DE SEGURANÇA NO TRABALHO}

\author{
Silvânia Rodrigues de Paula (1) \\ Edgard Thomas Martins (2) \\ (1) Universidade Federal de Pernambuco, mestre \\ silvania.rpaula@gmail.com \\ (2) Universidade Federal de Pernambuco Doutor \\ edgardpiloto@gmail.com
}

\begin{abstract}
RESUMO
Observamos o efeito do conhecimento sobre a identificação e sobre o controle dos riscos quando o comportamento do trabalhador realiza práticas seguras no ambiente de trabalho. O intuito é reduzir a probabilidade de eventos adversos e não planejadas. Podem ser estabelecidas ações específicas e direcionadas para prevenção de acidentes com a identificação de fatores cognitivos que contribuem mais fortemente para o comportamento humano durante a execução de atividades no trabalho, fazendo com que o trabalhador evite a repetição de acidente na mesma parte do corpo anteriormente envolvida, e também para evitar o envolvimento de outras partes do corpo em novos acidentes.
\end{abstract}

\begin{abstract}
We observe the effect of knowledge to identify and control the risks when the worker's behavior accomplishes safe practices in the workplace. The aim is to reduce the likelihood of adverse events and unplanned. They can be established specific and targeted actions to prevent accidents with the identification of cognitive factors that contribute more strongly to human behavior during the execution of activities at work, causing the worker to avoid the accident repeat the same part of previously involved body and also to avoid the involvement of other body parts further accidents.
\end{abstract}




\section{INTRODUÇÃO}

Podemos presumir nos dados da Previdência Social, último Anuário Estatístico de Acidentes do Trabalho - AEAT que no período de 2012 a 2014 ocorreram no Brasil 2.143.784 acidentes de trabalho (BRASIL, 2014).

Na tabela 1 são apresentadas as ocorrências de acidentes do trabalho considerando a situação dos mesmos em típico, de trajeto ou doença do trabalho.

Tabela 1 - Acidentes do trabalho, por situação do registro e motivos no Brasil - 2012 a 2014

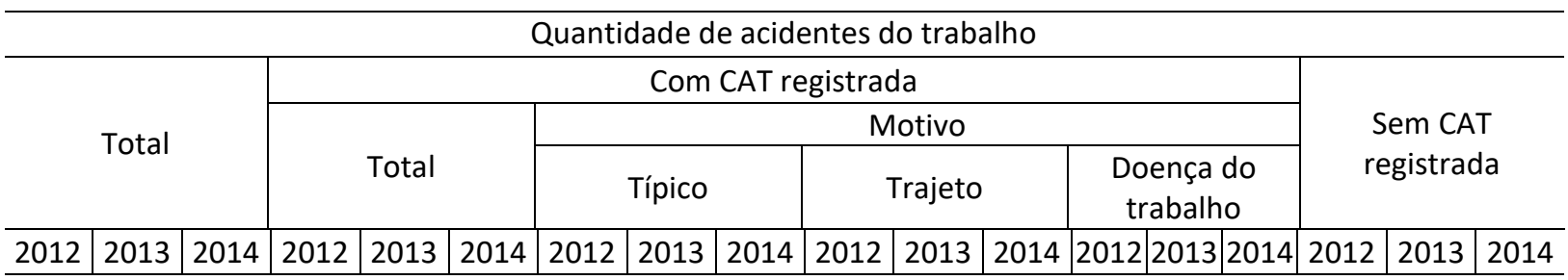

713.984725.664704.136546.222563.704559.061426.284434.339427.939103.040112.183115.55116.89817.18215.571167.762161.960145.075

Fonte: Dataprev, CAT apud Anuário estatístico de acidentes do trabalho (2014)

Na região Nordeste do Brasil diferente do desempenho Nacional, vemos uma redução na ocorrência de acidentes típico e no total conforme apresentado na tabela 2.

Tabela 2 - Acidentes do trabalho na região Nordeste do Brasil - 2012 a 2014

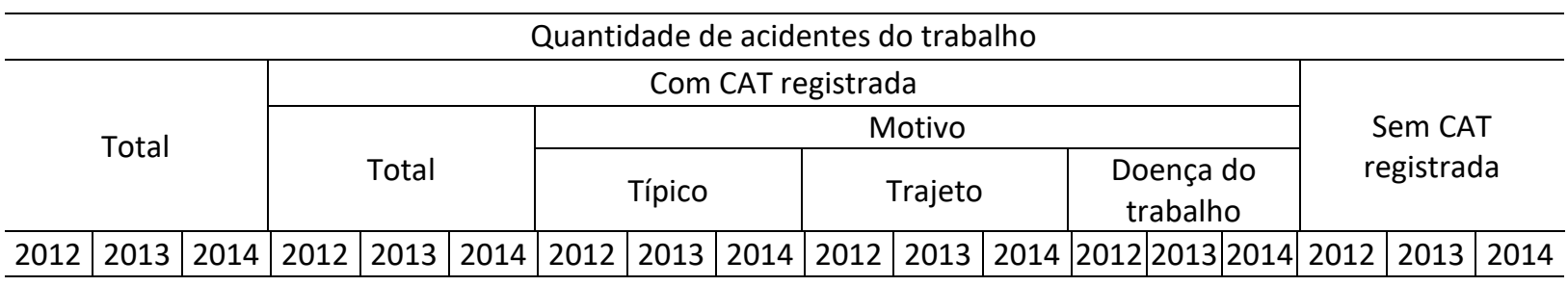

90.58888 .02785 .72256 .29155 .87256 .03142 .05740 .49039 .83411 .91312 .79113 .3552 .3212 .5912 .84234 .29732 .15529 .691

Fonte: Dataprev, CAT apud Anuário estatístico de acidentes do trabalho (2014)

O Estado de Pernambuco, conforme apresentado na tabela 3, demonstra redução na ocorrência de acidentes no ano de 2014 em comparação aos anos de 2012 e 2013. A ocorrência de acidentes do trabalho por motivo típico em 2014 teve aumento em sua ocorrência em relação ao ano de 2012 e redução em relação ao ano de 2013, não seguindo a tendência da região Nordeste, que foi de redução em 2013 e 2014. Os acidentes típico foram em maior quantidade que os acidentes de trajeto seguindo a tendência nacional nos anos de 2012, 2013 e 2014. 
Tabela 3 - Acidentes do trabalho, por situação e motivo - Pernambuco - 2012 a 2014

\begin{tabular}{|c|c|c|c|c|c|c|c|c|c|c|c|c|c|c|c|}
\hline \multicolumn{16}{|c|}{ Quantidade de acidentes do trabalho } \\
\hline & & & \multicolumn{10}{|c|}{ Com CAT registrada } & \multirow{3}{*}{\multicolumn{3}{|c|}{$\begin{array}{l}\text { Sem CAT } \\
\text { registrada }\end{array}$}} \\
\hline \multirow{2}{*}{\multicolumn{3}{|c|}{ Total }} & \multirow{2}{*}{\multicolumn{3}{|c|}{ Total }} & \multicolumn{7}{|c|}{ Motivo } & & & \\
\hline & & & & & & & Típico & & \multicolumn{3}{|c|}{ Trajeto } & $\begin{array}{c}\text { Doença do } \\
\text { trabalho }\end{array}$ & & & \\
\hline 2012 & 2013 & 2014 & 2012 & 2013 & 2014 & 2012 & 2013 & 2014 & 2012 & 2013 & 2014 & 2012 2013|2014 & 2012 & 2013 & 2014 \\
\hline
\end{tabular}

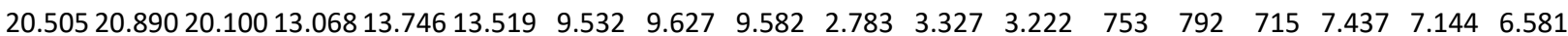

Fonte: Dataprev, CAT apud Anuário estatístico de acidentes do trabalho (2014)

Este desempenho mostra a necessidade de se aferir e auxiliar no processo de diagnóstico e análise dos acidentes que envolvem o comportamento do trabalhador buscando a redução sistemática da ocorrência para os que atuam nos sistemas organizacionais.

O comportamento do trabalhador em relação a realizar práticas seguras no ambiente de trabalho é decorrente da capacidade do mesmo ter conhecimento sobre como identificar e controlar os riscos da sua atividade, com o intuito de reduzir a probabilidade de consequências adversas para si e para outro trabalhador.

Vários problemas relacionados ao conhecimento em aspectos de segurança no trabalho podem estar presentes em caso de eventos adversos e merecem ser examinados, tais como: falta de instrução e capacitação, não entendimento completo das rotinas e procedimentos da empresa, tendência de relevar os perigos, manuseio inadequado de ferramentas ou materiais por falta de informação. Decorrente desta necessidade, os Ergonomistas vêm cada vez mais participando da identificação dos elementos da aprendizagem que contribuam para melhor desempenho na segurança no trabalho. "Os ergonomistas atuam, cada vez mais, contribuindo na concepção de sistemas de trabalho que favoreçam o desenvolvimento das competências e que assegurem a saúde dos trabalhadores e a segurança operacional". (ABRAHÃO, et al., 2009).

Os Ergonomistas atuam, contribuindo cada vez mais para a concepção de sistemas de trabalho que promovam o desenvolvimento de competências e assegurem a saúde dos trabalhadores e a segurança operacional, de acordo com Abrahão et al. 2009. Com a identificação de fatores cognitivos que contribuem mais fortemente no comportamento humano durante a execução de atividades no trabalho, podem-se estabelecer ações mais específicas e dirigidas para evitar acidentes.

Em virtude da necessidade das empresas de buscarem a redução e/ou eliminação de acidentes de trabalho, as mesmas cada vez mais treinam as equipes, identificam formas e sistemáticas para melhor gestão da segurança da saúde e segurança dos trabalhadores no âmbito da realização das atividades do trabalho. A partir da necessidade existente nas empresas, a ergonomia vem se desenvolvendo em seus estudos e aplicações. As empresas tem ampliado seu entendimento sobre a ergonomia, que vai além do caráter focado em aspectos físicos do trabalhador, passando a olhar o mesmo de modo mais completo, considerando os aspectos cognitivos envolvidos nas atividades desempenhadas pelos trabalhadores. 


\section{CONTEXTUALIZAÇÃO}

Os fenômenos comportamentais relativos à prevenção dos acidentes têm sido fonte de interesse e investimento por parte do governo, de empresas e de profissionais no que diz respeito à segurança no trabalho.

A prática da proteção cognitiva é uma obrigação legal e estabelecida em várias Normas Regulamentadoras do Ministério do Trabalho e Previdência Social, com destaque para a NR 1 - Disposições Gerais, (Brasil, Guia de Análise Acidentes de Trabalho, 2014). A legislação trabalhista no Brasil regulamenta que as empresas devem propiciar aos trabalhadores os conhecimentos e informações necessárias, habilidades e experiências de como lidar com situações de trabalho e como executar o trabalho com eficiência e segurança.

Considerando as informações sobre acidentes ocorridos no trabalho, no Brasil, nos permite aperfeiçoar diversos aspectos no sistema de gestão de segurança e saúde para os trabalhadores em seu âmbito de trabalho. O aperfeiçoamento nos aspectos apresentados na figura 1 contribui para a adequada gestão da segurança e saúde do trabalhador.

\section{Figura 1 - Elementos de gestão de saúde e segurança no trabalho}

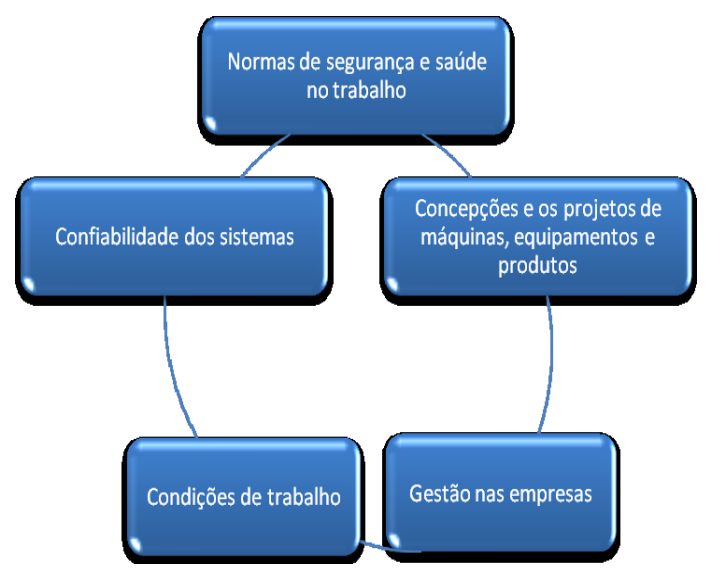

Fonte: Produção do próprio autor

É considerado que os fatores latentes geradores de eventos adversos são quase invariavelmente falhas de gestão, organizacionais ou de planejamento. (ANDRADE, 2010). Portanto, as análises de acidentes devem ser conduzidas de forma técnica para levar à minimização dos riscos de ocorrência de acidentes e não para procurar culpados, pois se assim for, as pessoas se tornam defensivas. Com a implantação de sistema de gestão que promova a capacitação adequada dos trabalhadores onde se possa contribuir para evitar a ocorrência de eventos não planejados, de modo que o trabalhador consiga transformar suas atitudes a partir de conhecimentos adquiridos em segurança no trabalho, haverá contribuição para a melhoria da saúde e comportamento seguro dos trabalhadores.

É importante ao analisar um acidente a classificação do tipo de falha humana cometida conforme figura 2 para então analisar as causas e estabelece as ações necessárias. 
Figura 2 - Tipos de falhas humanas

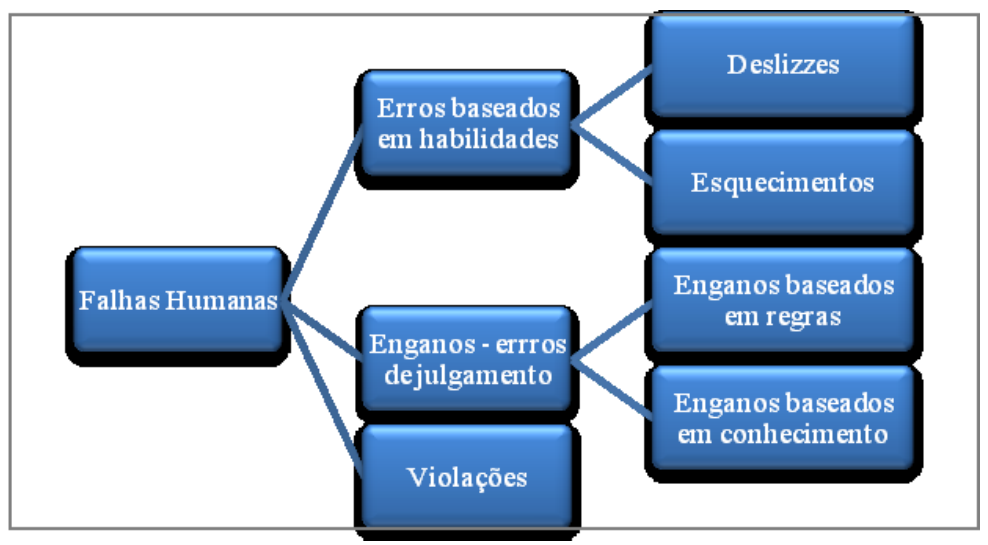

Fonte: Andrade, 2010

As falhas ocorrem por erros baseados em habilidades: deslizes ou esquecimentos. Deslizes acontecem quando o trabalhador realiza atividades automaticamente. A ação da pessoa não acontece conforme planejado. Quanto ao esquecimento (lapso) - este ocorre quando uma ação é feita fora da ordem habitual ou um passo da sequência planejada é perdido. Esses erros podem ser previstos e medidas podem ser tomadas para prevenir ou reduzir sua probabilidade. Falhas por enganos: erros de julgamento. Enganos baseados em regras acontecem quando o trabalhador tem diversas regras sobre o que fazer e aplica a regra errada. Enganos baseados em conhecimento - acontecem quando uma pessoa está diante de uma situação não familiar para a qual não tem regras. Nesse caso o trabalhador, utilizando seu conhecimento e experiência, chega a conclusões erradas. Para prevenir este tipo de falha, deve-se capacitar os trabalhadores, ter disponíveis procedimentos de trabalho seguros e completos e equipamentos com desenho e leiaute que permita a prevenção. Falhas de Violações (quebra de regras) - são falhas deliberadas ao seguir regras, onde o trabalhador usa atalhos ou artifícios para "ganhar" tempo e esforço, para aumentar a sua produtividade ou para melhorar aparentemente seu resultado.

Este artigo aborda o resultado, comparativamente, em três empresas quanto à repetição ou não da mesma parte do corpo envolvida em acidente típico após realização de treinamentos decorrente da análise dos acidentes no local de trabalho, quando estas empresas concluíram que as causas dos acidentes foram decorrentes de falhas humanas durante a realização de suas atividades. Na maioria dos acidentes tem-se o manuseio indevido de material em processamento, contato com partes das máquinas em operação e manuseio descuidado de ferramentas (martelo, estilete etc) durante a execução das atividades.

Os acidentes de trabalho registrados nas três empresas foram segregados por período de acontecimento em 2011 e 2012 conforme gráfico 1. 


\section{Gráfico 1 - Comparativo dos tipos de acidentes de trabalho registrados em 2011 e 2012}

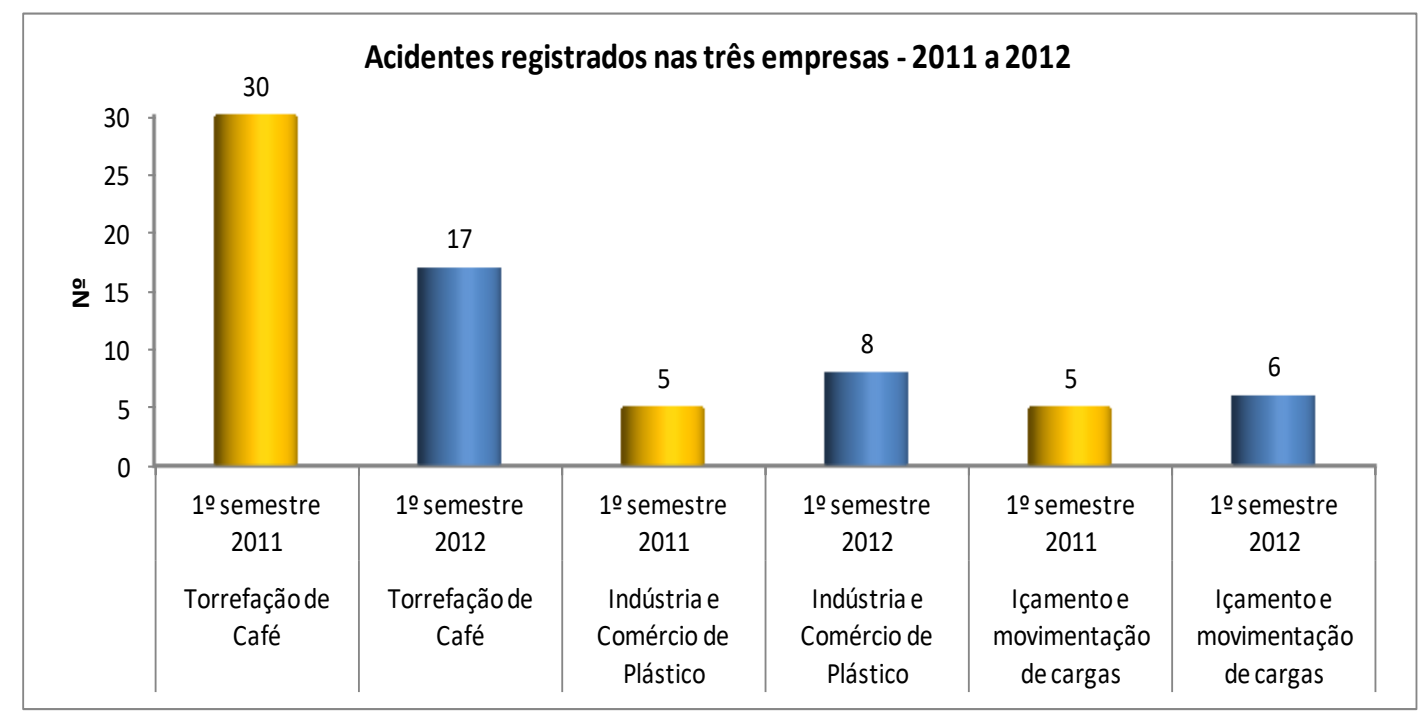

Fonte: produção do próprio autor

A tabela 4 apresenta os registros dos acidentes de trabalho agrupados por tipo em relação ao semestre em que os mesmos foram registrados, sendo estes, típico (objeto de estudo desta pesquisa) ou de trajeto para posterior análise mais detalhada quanto aos fatores que influenciaram na ocorrência dos mesmos.

Tabela 4- Acidentes de trabalho nas empresas do estudo - 2011 e 2012

\begin{tabular}{lccr}
\hline \multicolumn{1}{c}{ Segmento } & Semestre & $\begin{array}{c}\text { Tipo de } \\
\text { acidente }\end{array}$ & $\begin{array}{r}\text { Qte por tipo } \\
\text { de acidente }\end{array}$ \\
\hline \multirow{3}{*}{ Torrefação de Café } & $1^{\circ}$ semestre 2011 & Típico & 25 \\
& $1^{\circ}$ semestre 2011 & Trajeto & 5 \\
\cline { 2 - 4 } & $1^{\circ}$ semestre 2012 & Típico & 12 \\
& $1^{\circ}$ semestre 2012 & Trajeto & 5 \\
\cline { 2 - 4 } Indústria e Comércio & $1^{\circ}$ semestre 2011 & Típico & 5 \\
de Plástico & $1^{\circ}$ semestre 2011 & Trajeto & 0 \\
\cline { 2 - 4 } & $1^{\circ}$ semestre 2012 & Típico & 6 \\
Içamento e & $1^{\circ}$ semestre 2012 & Trajeto & 2 \\
\cline { 2 - 4 } movimentação de & $1^{\circ}$ semestre 2011 & Típico & 5 \\
cargas & $1^{\circ}$ semestre 2011 & Trajeto & 0 \\
\cline { 2 - 4 } & $1^{\circ}$ semestre 2012 & Típico & 5 \\
\hline
\end{tabular}

Fonte: produção do próprio autor

A partir da segregação e conhecimento da proporção da ocorrência de acidentes típico, que tem maior influência por parte do trabalhador, percebe-se pelo gráfico 2 , que tanto no ano de 2011 quanto para o ano de 2012, para as três empresas, os acidentes típicos 
representaram maior ocorrência, como era previsível, uma vez que o trabalhador permanece mais tempo nas empresas do que no trajeto para o trabalho ou para a residência.

\section{Gráfico 2 - Proporção dos acidentes típico em 2011 e 2012}

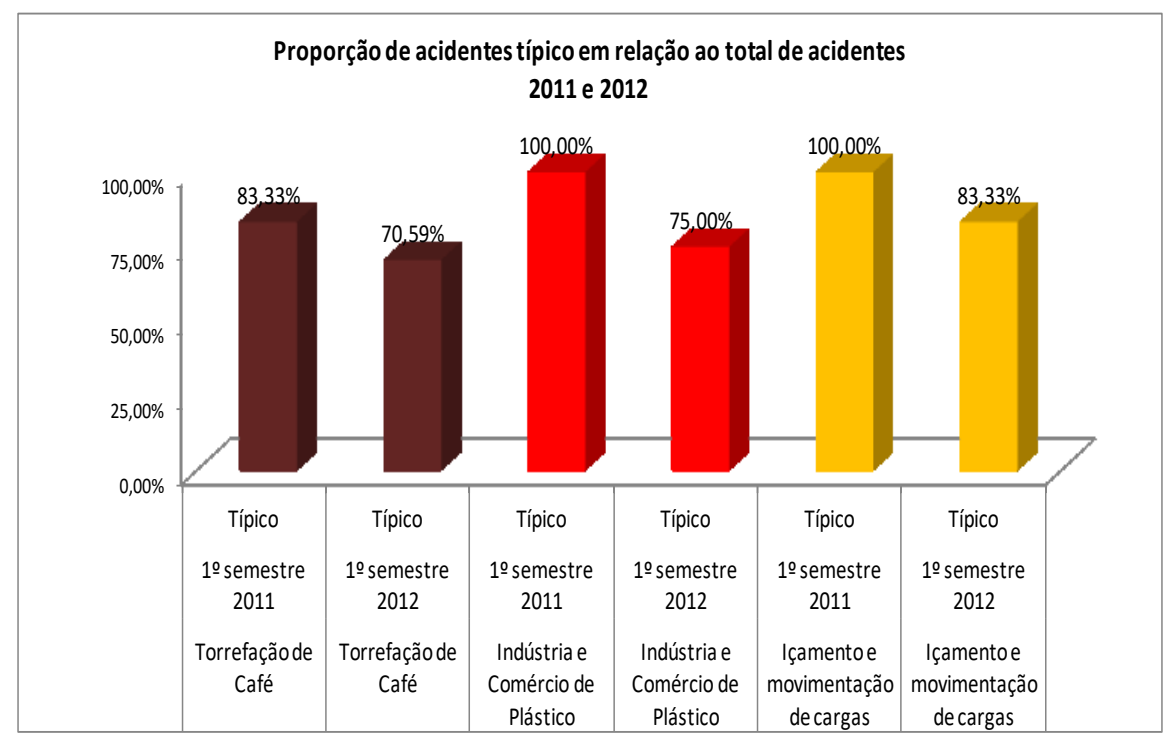

Fonte: produção do próprio autor

A partir da análise dos acidentes típico foi verificada redução da ocorrência deste tipo de acidente em cada empresa estudada..

Nas 3 empresas objeto de estudo desse artigo houve redução na ocorrência de acidentes típicos, ocorridos no local de trabalho, em relação ao período subsequente a realização dos treinamentos dos trabalhadores envolvidos com os acidentes. Onde a empresa A (torrefação de café) apresenta maior redução de ocorrência de acidentes típico, seguida da empresa $B$ (indústria e comércio de plástico) e a empresa B (içamento e movimentação de cargas) manteve o mesmo número de acidente típico conforme apresentado no gráfico 3

Gráfico 3 - Redução (\% ) de ocorrência de acidente típico 2012 em relação 2011

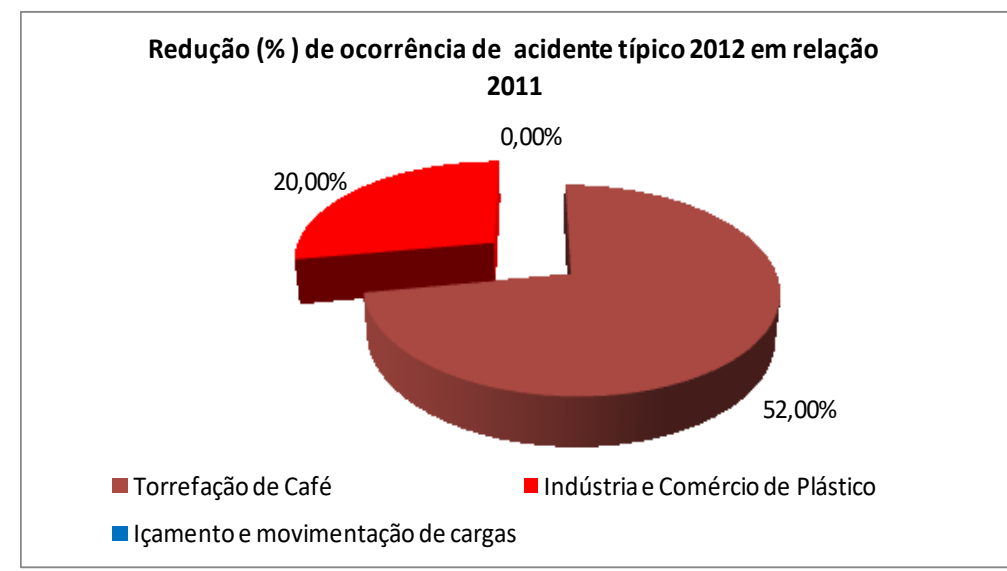

Fonte: produção do próprio autor 
As ações realizadas, após as ocorrências de acidentes típico com causas identificadas associadas a fatores humanos, foram referentes à realização de treinamentos e reuniões abordando os fatores humanos e as partes do corpo dos trabalhadores envolvidas com os acidentes de trabalho. As 3 empresas analisadas apresentaram redução de causas de fatores humanos envolvendo os acidentes de trabalho comparando-se o número de acidentes típicos por fatores humanos entre 2012 e 2011. A empresa A obteve redução de $45,45 \%$ de causas de fatores humanos, a empresa B teve redução de $40,00 \%$ e na empresa $\mathrm{C}$ não houve aumento de causas devido a fatores humanos conforme gráfico 4 .

\section{Gráfico 4- Redução de causas de acidentes por fatores humanos}

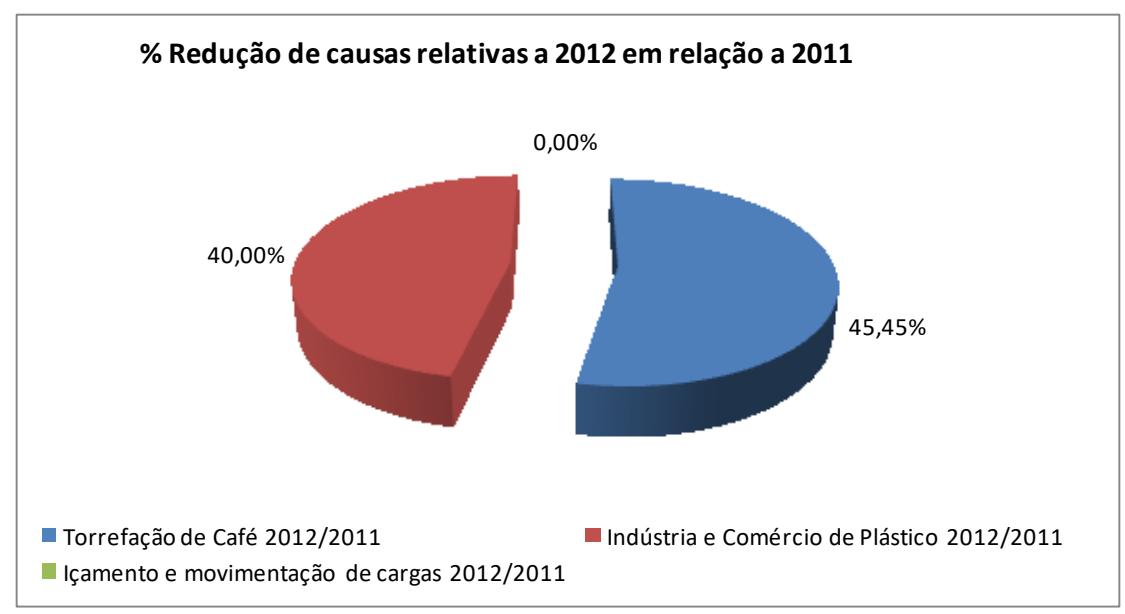

Fonte: produção do próprio autor

\section{MÉTODO}

A pesquisa foi desenvolvida como estudo de caso (multi-caso) em 03 empresas envolvendo segmento industrial e de serviços. A pesquisa foi do tipo exploratória para observar resultados de desempenho na segurança do trabalho após a aplicação de treinamentos. A pesquisa foi realizada em duas fases: a primeira referente à pesquisa bibliográfica no que diz respeito ao embasamento teórico sobre o tema para desenvolvimento da pesquisa prática. A segunda fase referente à pesquisa de campo com análise de relatórios de ocorrência de acidentes e treinamentos realizados com foco em segurança no trabalho.

Como instrumentos de coleta de dados na pesquisa documental foram considerados fontes primárias, tais como, documentos, relatórios da empresa objeto deste estudo e fontes secundárias como, por exemplo, registros dos acidentes no Ministério do Trabalho e Previdência Social, informações disponíveis na internet, livros, artigos e jornais. Para a análise e interpretação de dados foram estudadas e desenvolvidas etapas de coleta sobre as ocorrências dos acidentes no trabalho nos anos de 2011 e 2012, análise das informações consolidadas por empresa, elaboração de ilustração gráfica para melhor entendimento.

Foram também coletados os dados, e realizada interpretação com o objetivo de se ter informações consolidadas e comparativas acerca do problema para o qual se busca obter resposta.

A partir dos relatórios fornecidos pelas empresas foram identificadas as partes do corpo envolvidas com os registros dos acidentes típico, posteriormente, à aplicação dos treinamentos. 


\section{CONCLUSÃO}

Conclui-se que a redução dos fatores humanos apresenta-se como consequência da atenção dos trabalhadores a partir dos treinamentos realizados, gráfico 5 , tendo os funcionários melhorado o seu desempenho quanto à segurança no trabalho utilizando práticas mais seguras demonstrando que conseguiram transformar o conhecimento adquirido em comportamento.

\section{Gráfico 5 - Treinamentos realizados pelas empresas estudadas}

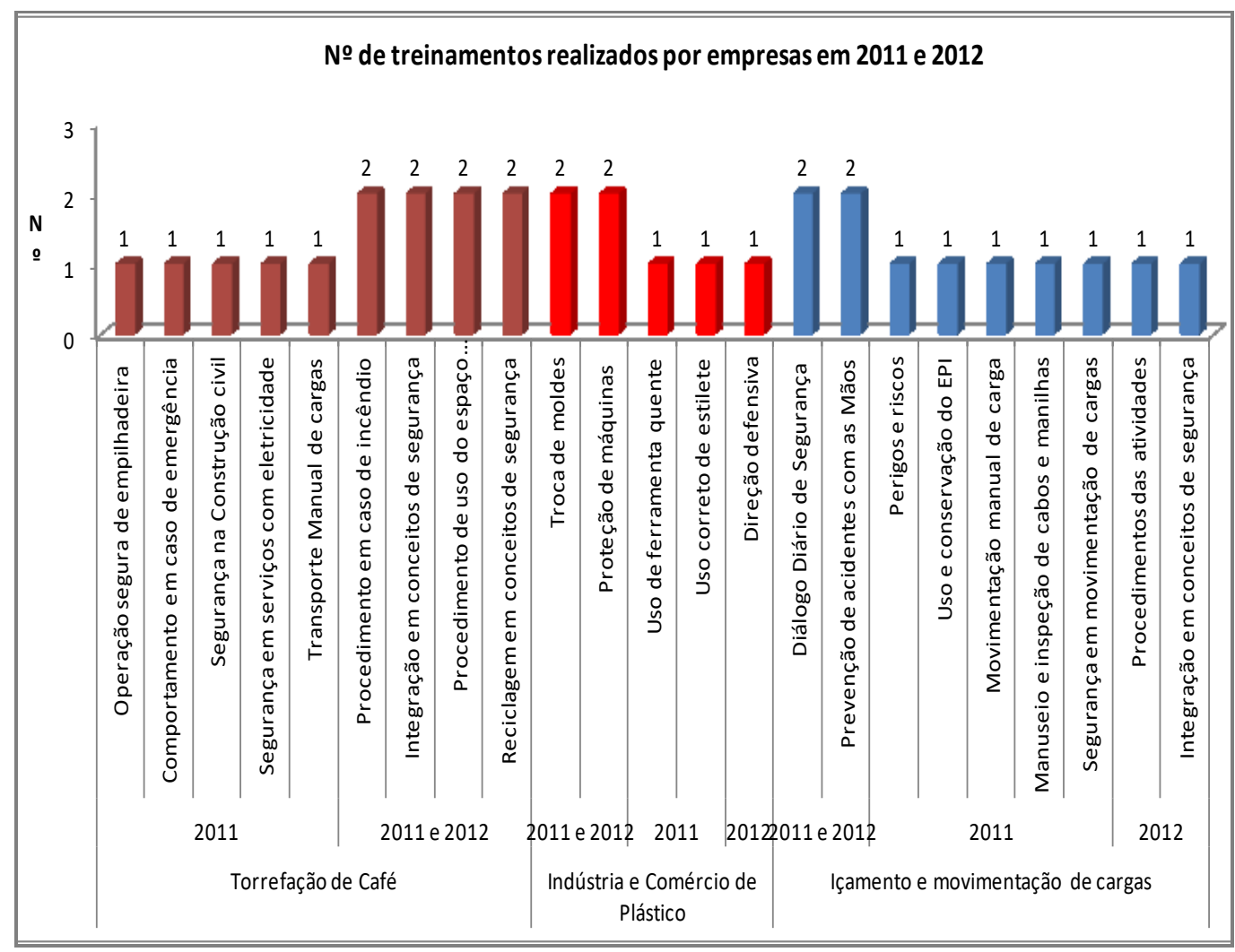

Fonte: produção do próprio autor

No entanto, percebeu-se ainda que os trabalhadores restringiram os cuidados e atenção necessários para as partes do corpo envolvidas diretamente com os treinamentos realizados, tendo portanto, novas partes do corpo envolvidas com acidentes em 2012.

Com a comparação dos dados entre as empresas, percebe-se que há realização de treinamentos, no entanto, com foco corretivo, não sendo percebido o desenvolvimento de temas preventivos, com a finalidade de ter-se uma cultura prevencionista, o que fica claro quando se observa que foram envolvidas em cerca de $40,00 \%$ das ocorrências, novas partes do corpo acidentadas, uma vez que os trabalhadores possivelmente restringiram os cuidados e atenção necessários para as partes do corpo envolvidas associadas com os treinamentos realizados, não ficando clara a percepção de risco para todo o corpo do trabalhador conforme demonstrado nos gráfico 6 , gráfico 7 e gráfico 8 . 
Gráfico 6 - empresa A - Comparativo de partes do corpo em acidentes - 2011 e 2012

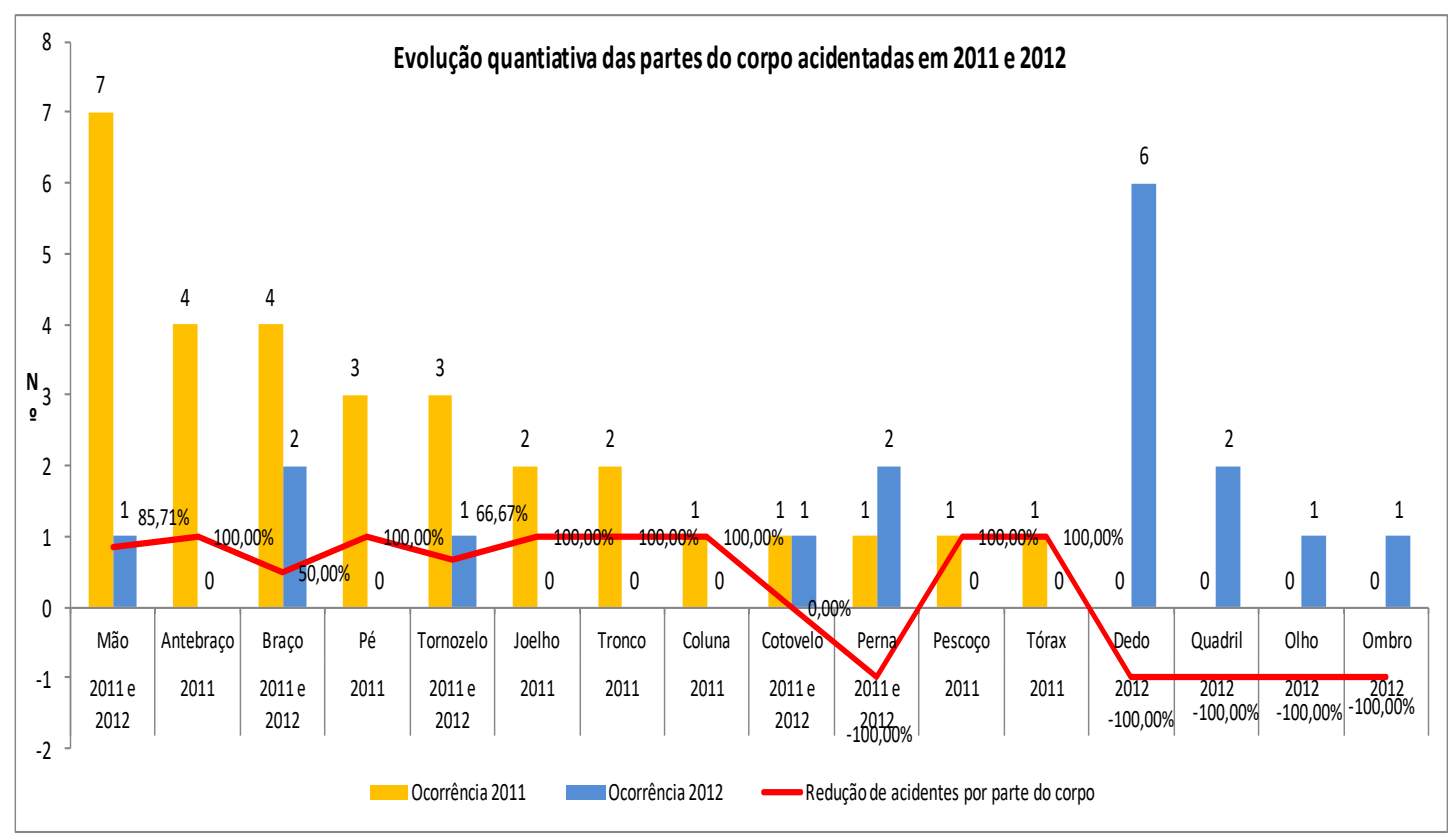

Fonte: produção do próprio autor

Gráfico 7 - Empresa B - Comparativo de partes do corpo em acidentes - 2011 e 2012

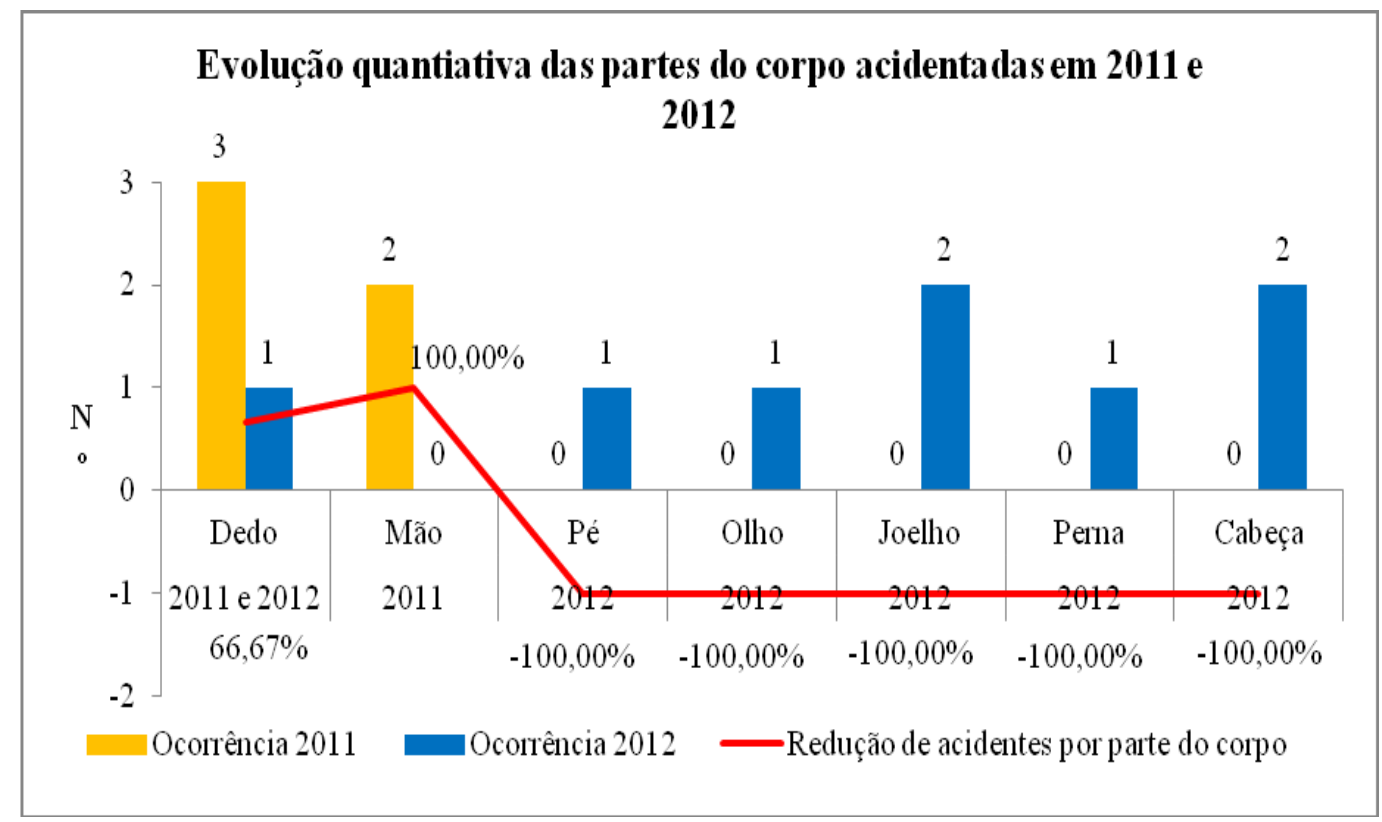

Fonte: produção do próprio autor 
Gráfico 8 - Empresa C - Comparativo de partes do corpo em acidentes - 2011 e 2012

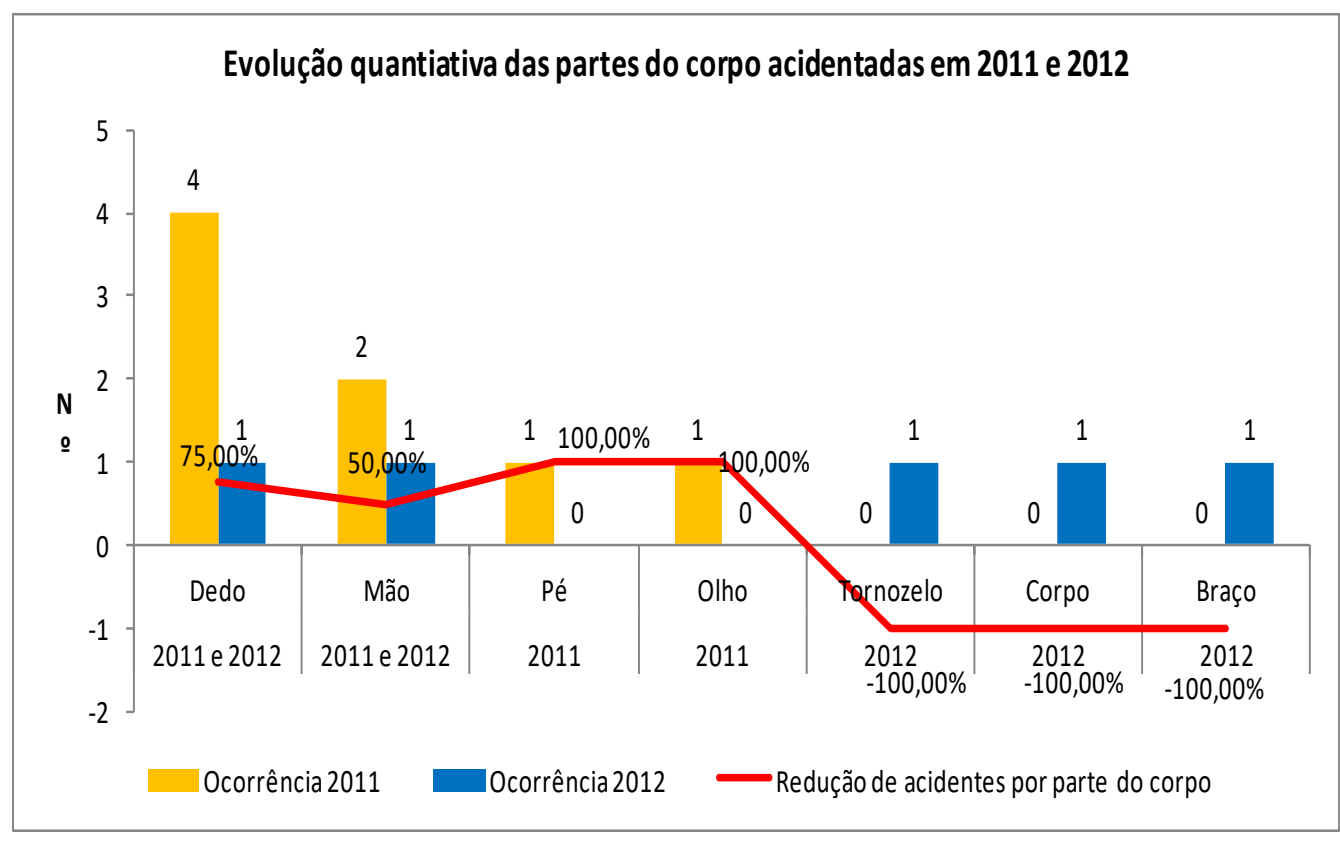

Fonte: produção do próprio autor

Quando da realização de novos estudos é importante considerar nível de escolaridade, traços de personalidade, aspectos cognitivos - memória, raciocínio, entre outros, como fatores de influência para potencializar os resultados, bem como a disciplina em cumprir as normas e procedimentos definidos na empresa.

\section{REFERÊNCIAS BIBLIOGRÁFICAS}

6.

ABRAHÃO, Júlia. Introdução à Ergonomia - da Prática à Teoria. São Paulo: Blucher, 2009.

ANDRADE, M.; BAUMECKER, I.C; FORTE, K. Guia de análise acidentes de trabalho. Brasília, 2010.

BRASIL. Ministério do Trabalho e Previdência Social. Instituto Nacional do Seguro Social. Anuário Estatístico de Acidentes do Trabalho: AEAT 2014. Brasília, DF: MTPS, 2014.

BRASIL. Ministério do Trabalho e Previdência Social. Secretaria de Inspeção do Trabalho. Guia de Análise de Acidentes do Trabalho: AEAT 2014. Brasília, DF: MTPS, 2014. 